\title{
El idioma del actor y la traducción infinita
}

\section{Laurent Berger

\author{
Profesor en la Universidad Paul Valéry, Montpellier 3 \\ Miembro del Laboratorio RIRRA21 \\ Investigador asociado a La Manufacture, Lausana \\ laurent.berger@univ-montp3.fr
}

Fecha de recepción: 16/4/2021. Fecha de aceptación: 12/05/2021

\section{Resumen}

Partiendo de la función de la traducción de una obra teatral para su versión escénica, indagamos en el proceso general de creación del espectáculo observando cómo el acto de traducción se multiplica y se despliega en realidad en todos los estratos de ese proceso. Concentramos esta reflexión en el trabajo del actor y su relación con el director, desarrollando el concepto de idioma interior, para analizar las diferentes operaciones de traducción que se utilizan para producir el espectáculo y su funcionamiento. Mostramos cómo esa dinámica de traducción nutre la creatividad actoral, permite penetrar el mundo interior del intérprete y genera regímenes cíclicos que transforman el trabajo de traducción en una tarea infinita.

Palabras clave: traducción, puesta en escena, actor, director, Shakespeare

\section{The language of the actor and the infinite translation}

\begin{abstract}
Starting from the function of translation of a drama play for its stage production, we investigate the general process of creating the performance, observing how the act of translation multiplies and actually unfolds in all layers of that process. We concentrate this reflection on the actor's work and his relationship with the director, developing the concept of inner language, to analyze the different translation operations that are used to produce the show and how they work. We show how this dynamic of translation feeds acting creativity, allows to penetrate the inner world of the actor and generates cyclical regimes that transform translation work into an infinite task.
\end{abstract}


La percepción de una traducción teatral en un espectáculo no se limita a su dimensión literaria. Se despliega también en elementos rítmicos, físicos o emocionales que le confieren una densidad compleja donde el texto es un componente entre otros y que no ocupa necesariamente el lugar central. Sin embargo, tenemos la costumbre de considerar la traducción como una operación principalmente lingüística, casi autónoma de la construcción del espectáculo, que se encarga de transferir el texto de un idioma a otro. Y aunque esa operación tome en cuenta, en el mejor de los casos, algunos criterios escénicos, en particular el hecho de que ese texto tiene vocación de ser expresado por un actor en un escenario, suele estar separada de la creación de la obra escénica. Valoramos de esta forma la traducción, porque en muchos casos esa operación se desarrolla en una etapa previa a los ensayos y es llevada a cabo por un traductor que no participa -o lo hace de manera limitada- en la siguiente operación, es decir, la escenificación de la obra; de esta forma la traducción constituye la base, más que la obra original, de la puesta en escena. Así lo defiende Antoine Vitez, director y a la vez traductor, cuando afirma que "Una gran traducción, por ser una verdadera obra literaria, contiene en sí su propia puesta en escena. Idealmente, la traducción tendría que dirigir la puesta en escena y no lo contrario" (1982: 6).

Pero es posible considerar la traducción como una obra de estatus híbrido, a la vez obra acabada, que se sostiene y se puede analizar e interpretar por sí misma, como lo desea Vitez, y a la vez intermediaria, porque, para que llegue el texto original al espectador, falta todavía toda la dimensión escénica que sigue transformando la obra original y le añade muchas capas interpretativas que diluyen o digieren la operación inicial de traducción en un movimiento mucho más amplio de mutación. En este segundo caso, observamos que muchos de los procedimientos que se desarrollan en la operación de traducción se prolongan en la interpretación del actor con una continuidad que merece atención y que relativiza, y a la vez ensancha, la noción misma de traducción, para integrarla en un proceso complejo de creación de la obra que trataremos aquí de explicitar.

\section{El texto y su limbo}

El acercamiento de un director a un texto teatral es un fenómeno singular donde la dimensión literaria de la obra puede ser determinante en primera instancia pero que rápidamente, o inclusive desde un principio, pone en juego otras dimensiones más intuitivas, inconscientes o metafísicas que empiezan a poblar su imaginario de interpretaciones personales muchas veces contradictorias con el propio texto. Más que determinar una interpretación explícita de la obra, el director trata de abrir su sensibilidad para penetrar el limbo que compone la multiplicidad de interpretaciones potenciales de la obra hacia su devenir escénico, limbo que le permite percibir y también crear una atmósfera donde encontrar elementos susceptibles de generar una visión de la obra. Esa visión es expansiva, pues consiste en una exploración imaginaria de un mundo todavía por inventar y el texto, o su traducción, es uno de los numerosos soportes de esta exploración, pero no siempre el más decisivo.

En particular, cuando uno trabaja sobre una obra de repertorio, no se puede ignorar que existe de antemano una visión latente de la obra, una presencia invisible, anterior a la lectura, o heredada de lecturas anteriores, de espectáculos pasados, de la existencia de la obra como mito o de las múltiples incursiones de esa obra en el campo del pensamiento colectivo, de la filosofía, de la literatura y de muchos otros campos de la experiencia humana. Asimismo, una obra teatral, más allá del texto, está atravesada por todo el universo del autor, y los propios personajes conforman, en esta etapa exploratoria, un caleidoscopio donde se reflejan otros personajes de la misma obra, del mismo autor, o personajes espejos. Esto se produce por las numerosas asociaciones 
que genera, en la historia de la literatura, la relación con obras posteriores, y también con personajes de obras anteriores a la obra misma. Para Yves Bonnefoy, traductor de Shakespeare al francés, es claro que una pieza nos abre al campo entero de la sensibilidad del autor:

Miren a Hamlet, por ejemplo, esta presencia irracional que ninguna descripción objetiva podría reducir a una fórmula cerrada, autónoma. Hamlet sólo cobra verdaderamente su significado si reconocemos en ella esa gran metáfora por venir, inconsciente en parte de sí, abierta, por la cual el mismo poeta, y no algún personaje que él imagina, se proyecta en lo expresado; y sólo si sabemos, por consecuencia, entender bien que el verdadero drama y las verdaderas tensiones aparecen tanto en esa duración donde Hamlet y Leontes y Próspero se suceden (donde Shakespeare se profundiza y trata de aclararse) como en el conflicto aparentemente cerrado sobre sí mismo que opone el joven príncipe a su madre o al nuevo rey (1982: 51).

Nuestra imaginación nos invita efectivamente a penetrar a través de un texto el mundo entero del autor, pero más allá de Shakespeare, el personaje de Hamlet nos remite también a figuras dramáticas inspiradas directamente o indirectamente en él, como Treplev en La Gaviota, que constituye una especie de traducción de Hamlet en el universo chejoviano, o a piezas como Máquina-Hamlet de Heiner Müller. Y también nos remite a figuras anteriores a él, ignorantes de su existencia, pero que pertenecen a la visión latente que tenemos de la obra, como Orestes o Edipo, por ejemplo, obras hamletianas en tanto que encarnan la problemática de la venganza, del incesto o de la duda ante la acción e imitan, de antemano, estructuras psicológicas y dramatúrgicas de la obra futura. Porque en el campo abierto que es la construcción del imaginario de una obra escénica, la pieza textual no tendría que delimitar fronteras, por muy amplias que sean, para la interpretación.

Por supuesto que para directores más aferrados a una visión literaria del teatro, la exégesis del texto original sigue siendo la piedra angular de la producción escénica. Pero, para otros que otorgan un valor predominante a esa dimensión escénica, la resolución del proceso de creación obliga a eludir, por momentos, las implicaciones del propio texto teatral, para ocupar terrenos imaginarios que sintonizan con la obra escrita, pero que quedan afuera de su territorio de control. Para decirlo de otra forma, en ese tipo de procesos, la construcción conceptual del espectáculo no requiere sistemáticamente volver al texto para desarrollarse. En ese sentido, la idea de obra latente, ese limbo de interpretaciones, imágenes y asociaciones que envuelve la obra original, pero expande considerablemente su dominio, permite una libertad de exploración indispensable para introducir elementos nuevos y decisivos que hacen pasar la obra textual al escenario. Porque en la configuración de un proyecto escénico muchas veces las intuiciones se adelantan hasta a una primera lectura de la obra.

Por ejemplo, vamos a decidir montar la Ópera de dos centavos de Brecht porque tenemos una idea para modernizar el concepto de espectáculo musical y podemos desarrollar esa idea independientemente del texto, y volver al texto una vez que el concepto escénico está lo suficientemente maduro para reconfigurar la obra. La lectura de la obra interviene, entonces, para nutrir ese concepto y la abordamos como una etapa más de la creación, con ese objetivo en mente, más que como una labor interpretativa que daría pie a la formulación del concepto escénico. O bien imaginamos un dispositivo visual o performativo y vamos a buscar un material textual que sea un buen combustible para hacer funcionar ese dispositivo. Entendemos que en una visión contemporánea de la obra teatral, la formulación y la propia materialidad del espectáculo son distintas, por esencia, de la forma textual, y no una extensión o una derivación de esa forma. 


\section{La traducción excéntrica}

Sin embargo, aunque la traducción sea una disciplina estrechamente ligada a la literatura, las dinámicas que implica pueden ser fructíferas a la hora de entender el proceso de creación para la escena y en particular para describir algunos matices del trabajo del actor.

En una primera instancia, si abordamos la traducción como una simple transferencia de un conjunto de significados y significantes de una obra poética, esa operación puede parecer reductora y hasta frustrante, al punto que se cuestiona la legitimidad misma de tal acción (Bonnefoy, 1982: 50). En una obra de teatro que se define por su multiplicidad interpretativa, la traducción parece contribuir a una destrucción programada de la obra original. Para Jean Louis Barrault, inclusive, puede llegar a ciertos niveles de vandalismo:

La entrada de Shakespeare en Francia empieza por un crimen. Shakespeare, atravesando el canal de la Mancha sufre una operación que se asemeja al vandalismo: lo amputan de su forma verbal. Shakespeare, que es puro arte y cuyo pensamiento aparece mucho más en su poesía que en su razonamiento, ve en general sus alas lamentablemente cortadas por nuestra lógica. Sin ritmo, sin música, sin niebla, incluso sin esos puntos oscuros, esos rincones hasta ahora inexplorados y protegidos con celos por los enamorados del poeta (Barrault, 1949: 10).

Y aún cuando no se hace hincapié en la destrucción de la obra original, la traducción suele representarse como una empresa imposible que no alcanza a ofrecer un equivalente a las múltiples dimensiones, rítmicas, semánticas o metafóricas de la obra. Muchos son los traductores que insisten, de hecho, sobre las contradicciones a las cuales se enfrentan y cuya resolución siempre implica un compromiso y asume la pérdida de algunos de los matices del texto original:

Una traducción es siempre un compromiso, un equilibrio, entre dos necesidades contradictorias: entre modos de expresiones de dos idiomas, entre lenguajes de dos épocas distintas la una de la otra, entre -en particular en poesía- el sentido riguroso del original y las exigencias formales, entre meticulosidad semántica y vida del texto, entre el ojo del lector y el oído del oyente. Elegir una opción en detrimento de las otras, por supuesto es traición. Siempre pensé, por mi parte, que el rol del traductor era de dar lo máximo posible del sentido, lo máximo posible de la forma, lo máximo posible de la voz propia del autor original (Malaplate, 1991: xxii).

Sin embargo, esa sensación de estar siempre por debajo de una cima inalcanzable, encarando una lucha perdida de antemano, puede ser invertida si nos ponemos a considerar la traducción no tan sólo como un objeto final (y por lo tanto un objetivo), sino como una herramienta o una etapa del proceso de transformación e interpretación de la obra.

Concretamente se trata de empezar a usar la traducción en una dimensión cumulativa y asociativa en vez de dejarse limitar por una relación exclusiva a la lengua. Se puede empezar a establecer estos principios ya en el nivel propiamente literario, favoreciendo las potencialidades múltiples de la traducción en lugar de sus facultades interpretativas y de elucidación del sentido. Jean-Claude Carrière, por ejemplo, traductor y adaptador para Peter Brook en su período francés, trata de mantener la calidad radiante del verbo shakesperiano:

Entre los dos peligros que son la traducción llana y la excesiva poetización el camino es muy estrecho $y$, para seguirlo, uno tiene que encarar una doble tarea: 
primero encontrar en el texto de Shakespeare lo que llamamos las palabras radiantes, las palabras claves, que son los soportes polisémicos, y después encontrar los equivalentes en francés, porque siempre existen, soy categórico sobre este punto. Una vez que hemos trazado este camino, buscamos las aliteraciones, cuando existen (1982: 42).

Pero más allá de la relación dual entre el texto original y su traducción, también se puede tomar en cuenta la traducción en su perspectiva histórica superando la singularidad de una traducción, y contemplando cada una como una capa suplementaria que complementa los estratos existentes de las traducciones anteriores para formar un substrato textual complejo y múltiple donde crece la creación. Así lo observa Daniel Mesguich quien considera que la traducción de Hamlet por Michel Vittoz:

Traduce del francés al francés, traduce Gide, Bonnefoy, François-Victor Hugo, no traduce "ser o no ser" porque sabe que ya pertenece al repertorio francés. Parece haber sido traducida por traductores distintos en distintas épocas. Está en contradicción permanente y reactiva permanentemente su propia heterogeneidad (1977: 31).

Aunque esta visión puede parecer un tanto metafórica, porque al final la traducción obliga a elegir un término entre otros, si la miramos a nivel de la labor actoral se vuelve muy concreta, porque aunque un actor sólo pronuncia una palabra, su trabajo psicofísico se puede nutrir de muchas otras.

Entonces, en vez de estar bajo la atracción concéntrica de la traducción (la elección de una palabra entre las muchas que ofrece el idioma de traducción) empezamos a aprovechar su energía excéntrica (el uso de las múltiples variantes que generan las diferentes traducciones posibles). Es como si estuviéramos montando varias versiones del texto al mismo tiempo, como sugiere Antoine Vitez: "Si la traducción es magnífica, entonces montamos la obra original y su traducción. La traducción también se vuelve objeto de la puesta en escena" (1982: 7).

Por otra parte, una visión excéntrica de la traducción también nos invita a relativizar la noción de pérdida entre idioma original e idioma meta, valorando los aportes del idioma original a la lengua de traducción:

Traducir el verbo shakesperiano significa que uno multiplica su propio idioma, ya que estamos forzados a remontar en él hasta ese lugar mítico de la lengua original por caminos que, atravesando la lengua materna, la carga del peso de los mundos recorridos, que piedra tras piedra ensamblamos y ajustamos. Y así estamos forzados a encontrar arquitecturas inéditas a las cuales el pensamiento no está obligado cuando escribíamos en nuestro propio idioma - como un río cambiando de curso ahonda en su cauce (Pasqual, 1989: 2).

En cuanto reestructura nuestra propia lengua forzándola a adoptar comportamientos correspondientes al idioma original, la traducción la enriquece y abre nuevos campos para la interpretación del actor. Nos obliga a desarrollar nuevos reflejos.

La traducción pasa de ser un objeto único y estable a representar una herramienta potente de exploración y transformación tanto semántica como simbólica del imaginario que estamos creando para la obra escénica. De esta forma, la traducción, además de su función lingüística primera, se desdobla para poblar otros espacios de la creación, como puede ser la dimensión psicológica, cultural, visual o también performativa de la obra, de materiales distintos a los que ofrece para la constitución del texto escénico. En este sentido, deja de ser la prerrogativa exclusiva del 
traductor y se puede entender, desde un punto de vista más colectivo, como una tarea a la cual contribuyen tanto actores como directores o escenógrafos.

\section{El traductor total}

Esta visión de la traducción a una escala que desborda ampliamente la cuestión del texto escénico, encuentra una potente justificación considerando en particular la importancia del actor en el hecho teatral. Si realmente tomamos en cuenta el recorrido completo de la materia textual, desde el texto original hasta el momento de la representación, entendemos que el lenguaje genuino del teatro es el del actor, porque es en él donde acaba el viaje lingüístico desarrollado por la puesta en escena. Desde este punto de vista, la traducción teatral se puede considerar incompleta sin ese componente vivo y carnal que enriquece la dimensión propiamente lingüística. ¿Cómo se configura esa labor de traducción que se extiende más allá de la constitución del texto escénico?

Se basa, en primer lugar, en una manera diferente de concebir la traducción lingüística. Y aquí, las reflexiones de los directores que producen sus propias traducciones de las piezas son de mucho valor, porque las toman en consideración dentro del curso completo de la creación del espectáculo. Ariane Mnouchkine, por ejemplo, confiesa que "su tarea consiste en traducir el material que el autor original daba a los actores. Las personas que tienen poco contacto con la realidad del teatro y con los actores procuran seguramente que sus traducciones sean autosuficientes, olvidando que la actuación es el relevo del texto" (Mnouchkine, 1982: 9). El trabajo sobre la transformación del texto anticipa la posibilidad de culminación de esa tarea lingüística a partir del material actoral, como si el texto, penetrando en el escenario, cambiara de naturaleza y siguiera transformándose empleando otros modos de expresión para seguir profundizando el misterio de la obra.

En ese proceso heterogéneo donde la traducción se prolonga en la actuación, la jerarquía entre traducción y actuación puede ser incluso invertida. Si consideramos que la traducción es un camino que tenemos que encontrar entre la obra original y la obra escénica, se puede ir descubriendo y transitando a partir de su punto de llegada; entonces, el ensayo escénico se vuelve acto precursor de la traducción lingüística porque pertenece a un mismo proceso de creación.

Los ensayos son el banco de pruebas de mi propia traducción. A menudo, el texto de Shakespeare propone una multiplicidad de sentidos que no puedo preservar al nivel de la traducción, porque a veces hay que elegir un solo sentido entre varios. A través de la dirección de actores, ya que sé perfectamente lo que he perdido del texto original, trato de restituir la multiplicidad de sentido inicial. La actuación le devuelve al texto lo que no sé captar en el papel y entonces el director que soy palía las pérdidas de riqueza que se generan al nivel de la traducción (Seide, 1982: 60).

Esta concepción de la traducción la vuelve porosa al trabajo con el actor y viceversa, y altera profundamente el orden jerárquico y temporal de la construcción del espectáculo. Nos invita a considerar la traducción del texto de manera más compleja y sorprendente, como parte de una traducción total a la cual contribuyen actores y directores, y que toma como zócalo no solo la obra textual original, sino una obra secreta e invisible que vamos percibiendo a medida que la estamos montando, y que incluye elementos de la pieza original, pero también intuiciones y conceptos independientes ligados a la propuesta escénica en sí. También nos obliga a actualizar los procesos de ensayo mezclándolos con los de la escritura, privilegiando un acercamiento desde la contemporaneidad y basado en la creatividad escénica 
respecto a un punto de vista más artesanal y programado, anclado en el texto del autor. Al mismo tiempo, autoriza la irrupción del texto original a cualquier momento del proceso para enriquecer el contenido del espectáculo, saltando el filtro de la traducción textual. Se genera un continuum de materiales heterogéneos, compuesto del texto original, de varias traducciones (incluso en varios idiomas), del texto escénico todavía en gestación, como también de materiales dramatúrgicos aditivos o experiencias de ensayos, que todos requieren una traducción en el escenario. El acto de traducción textual se disuelve en una tarea colectiva llevada a cabo por el conjunto de artistas que trata de trasladar (más que traducir) un objeto literario y el universo que conlleva hacia una realidad material, carnal y temporal, enriqueciéndolo en el camino con diferentes materiales y motivos producidos por el propio sistema de ensayo. Y dentro de ese modelo, son los actores los agentes últimos de la tarea y por lo tanto las terminaciones verdaderas de las múltiples transformaciones que genera el proceso de creación escénica.

\section{El idioma indescifrable del actor}

Como hemos visto, la traducción lingüística de la obra es tan solo uno de las componentes de un sistema más complejo de traducción que se desarrolla en el seno de la fabricación del espectáculo y donde los actores llevan un papel determinante como articulación y receptáculo final del texto escénico, pero también como productores de parte de esa traducción total de la cual hablamos. Para eso, el actor usa recursos propios que se apoyan, en parte, en su percepción íntima de los idiomas donde intervienen cuestiones culturales, pero también orgánicas. En una mezcla de conocimiento lingüístico y de intuición sonora y vocal, el actor desarrolla un sistema de distribución del sentido y de la forma que solo le pertenece a él, y cuyo funcionamiento es, en gran parte, indescifrable. Así, para Bruce Meyers, actor inglés de Peter Brook que trabaja en sus puestas en escena francesas a partir de 1970, actuar Shakespeare en francés es un privilegio más que una traba, ya que le permite explotar recursos nuevos donde conjuga su conocimiento dispar de los dos idiomas para inventar un nuevo modo de expresión.

No se trata de preservar el gesto que se sitúa atrás de la frase inglesa, sino una cuestión de sentido. No puedo jugar con la resonancia ni la cadencia de las frases inglesas. Estoy obligado a trabajar sobre la musicalidad propia al francés. Claro, a menudo la traducción hace perder fuerza al texto. Pero a veces es al inverso. El hecho de saber que el original es más potente para ciertas cosas me da la curiosidad de buscar el equivalente en la lengua francesa. Me han dicho muchas veces que cuando es perfectamente clara, mi manera de hablar puede dar a las ideas del texto un toque más claro. Y en esos momentos, la idea misma de acento se desvanece (Meyers, 1982: 73).

Su peculiar situación cultural le ayuda a reconfigurar la poética del texto y crear un sistema de traducción que ya no se funda en la translación de un idioma a otro, sino que nace literalmente de la superposición de los dos idiomas en una mezcla inimitable y exclusiva. Esa traducción propia, hija única de los dos idiomas tal como están encarnados en el actor, es intransferible a otro intérprete. Son brotes personales y secretos, en parte inconscientes, que enriquecen la traducción textual de tantas capas como actores capaces de aportar su percepción original del idioma, creando, por así decirlo, una traducción actoral por encima de la traducción textual, y vertiendo esa visión al servicio de la singularidad de su personaje.

De este modo, el actor termina abriendo el concepto de traducción a espacios que escapan a una explicitación idiomática, porque su sensibilidad transfiere el texto y su 
significado a una dimensión física y emocional que difícilmente se puede explicitar con palabras. Su idioma actoral es atravesado por la lengua del autor y la del espectáculo, pero su traducción irradia también en lenguajes no verbales conformando un idioma escénico complejo y desconocido. Además la propia situación teatral, enfrentándolo cotidianamente al público, genera una necesidad de renovar permanentemente ese sistema de traducción.

Al contrario del traductor que trabaja a partir de una materia estable, el actor se enfrenta a una lengua móvil, agitada por las variaciones de los ensayos y de las funciones, la interpretación de los otros actores, los aportes cotidianos del director y sobre todo la posibilidad de añadir una capa interpretativa a su propia traducción con su aparato expresivo. Idealmente esa dinámica genera un régimen cíclico en el proceso de creación, pues la traducción actoral del texto aporta elementos decisivos y novedosos a la interpretación que pueden a su vez ser reflejados en el texto. En esos casos, la traducción escénica se puede entender como la composición de una base continua que permite estructurar la obra, y de la cual el texto escénico es la materialización con variaciones sensibles a la traducción actoral. Inclusive, en algunos montajes, el texto escénico es modificado de tanto en tanto durante las funciones, para incluir aportes decisivos de los actores a la partitura textual que merecen permanecer en la obra.

Pero, a pesar de su riqueza y dinámica, las contribuciones de los actores a la traducción global de la obra no dejan de generar dificultades durante los ensayos y en la construcción del espectáculo. Porque, al lado de la parte emergente, expresiva, del trabajo del actor, que puede ser discutida, incluso objetivada, subyace una parte oculta que genera esa expresión y que constituye el idioma interior del actor, un idioma invisible e intransferible con el cual el director tiene que dialogar para generar un lenguaje común al equipo artístico.

Parte del trabajo del director consiste en ese descubrimiento a ciegas de un camino colectivo donde trata de traducir intenciones y sentidos a un idioma desconocido. Entre la visión que procura transmitir y la traducción escénica con la cual el actor le responde, hay un mundo de incomprensión y de malentendidos que sólo el intercambio en los ensayos permite aclarar. Para Antoine Vitez, una herramienta decisiva de ese diálogo es la metáfora.

El trabajo de puesta en escena es sobre todo un esfuerzo de parábola perpetua, de perpetua metáfora, un esfuerzo poético EN LA LENGUA. La puesta en escena consiste en hablar a los actores de OTRA COSA que lo inmediato. No basta para nada decir a un actor de ir a la izquierda, a la derecha, de hablar más alto... hay que usar comparaciones, metáforas que apelan a su vida cotidiana, a toda su memoria. Por lo tanto, hay que conocer esa memoria. Y esa memoria, es LA LENGUA, la inmensidad de la lengua (Vitez, 1978: 19).

Dirigir al actor a partir de su expresión escénica constituye una vía demasiado explícita y demasiado condicionante, para que el actor pueda desarrollar su propio lenguaje. El objetivo es nutrirse de la obra para inventar un lenguaje compartido con el cual poblar el imaginario colectivo del equipo artístico. Un lenguaje bastante abierto para que cada actor pueda traducirlo en su propio idioma interior y bastante elaborado para configurar una poética a partir de la cual esos idiomas personales tan distintos puedan intercambiar con cierta sintonía. La precisión de la metáfora agudiza el sentido sin cerrarlo, permite un amplio abanico de interpretaciones que se despliegan como variaciones armónicas de una misma nota. Es una herramienta idiomática, pero apela al inconsciente, puede apoyarse en la fuerza del texto, pero ofrece líneas de fuga que se escapan de él. 
Así, paralelamente al lenguaje textual de la obra, se constituye poco a poco otro idioma, invisible para el espectador, pero presente en el imaginario de todos los actores, un lenguaje propio a cada montaje que los actores aprenden a dominar durante los ensayos y a traducir en su propio idioma interior. Se trata de un lenguaje híbrido, una interfaz, con una capa explicativa que da una orientación determinada y común a la obra escrita, por un lado y, por el otro, una capa multifacética que permite conectar los distintos imaginarios actorales.

Sin embargo, este componente imaginario del espectáculo dialoga de manera demasiado indirecta con los aspectos más materiales y expresivos de la obra y del trabajo del actor, para influir sobre la composición plástica y sonora de la obra. Para penetrar esa faceta del trabajo del actor es indispensable adentrarse en la dimensión corporal de la puesta en escena. Y allí también yacen malentendidos sutiles entre director y actores. Pues si existe un desconocimiento profundo del lenguaje interior del actor, eso incluye también su funcionamiento orgánico.

Por supuesto, la traducción de la obra en un lenguaje corporal compartido es facilitada por su dimensión perceptible, y la interacción cotidiana de los cuerpos participa de la construcción de ese lenguaje. La fuerza mimética permite incluso trasladar poco a poco las intenciones estéticas de la obra a un idioma sin palabras que el cuerpo del actor reconoce y adapta a su dinámica propia. Si en una primera instancia esos objetivos pueden necesitar una traducción lingüística de parte del director para explicitar ciertos principios artísticos, muchas veces la comunicación no verbal es más eficiente, y el actor traduce desde su cuerpo a su lenguaje interior con más efectividad, que a partir de una formulación intelectual que desconoce demasiado su sistema orgánico de expresión.

Poco a poco, inclusive hablando idiomas corporales distintos, el actor va traduciendo en su lenguaje propio las expresiones que le propone el director, hasta encontrar una sintonía donde el actor se apodera completamente de los movimientos imaginados por el director.

Le daba todo tipo de indicaciones que actuaba para él, indicaciones que él no podía físicamente realizar: mi cuerpo, mis movimientos, no tienen ningún tipo de equivalente con los suyos. Lo absorbió todo, confió totalmente en mí, y, finalmente, lo que quería ver aparecer cuando actúa, es una especie de TRADUCCIÓN, de reinvención de lo que yo le había sugerido. Y ahora es sin duda ÉL quien lo hace. No se me parece en nada. Pienso en esta fórmula de Stanislavski que dice que el director debe MORIR en el actor (Vitez, 1978: 19).

Una vez más, este trabajo de traducción corporal del actor se desarrolla sin poder descifrar, por parte del director, el funcionamiento profundo y los secretos de su lenguaje. Solo la experiencia compartida del ensayo permite esa transferencia a un idioma desconocido que pertenece totalmente al actor.

Aunque se le parezca en muchos aspectos, la labor de traducción del director impacta de manera todavía menos directa en la obra escénica, que la del traductor que forja con su imaginación las palabras del escenario. Colocada entre la obra escrita (y traducida) y la interpretación viva del actor, la función del director consiste en producir un lenguaje efímero que el actor va digiriendo a lo largo de los ensayos hasta apropiárselo entero y que se desvanece cuando la obra se actúa.

\section{Los vestigios de la obra y la eterna profanación}

Más allá de las cuestiones lingüísticas, la traducción es un fenómeno consubstancial a la creación escénica. Por los múltiples lenguajes que se cruzan en un escenario, el 
del autor, del traductor y de los actores, la necesidad de traducir es permanente e imperiosa y sus potencialidades parecen infinitas.

Por una parte, porque la traducción textual puede resetear muchas de las implicaciones de la obra original y ofrecer terrenos nuevos a la interpretación; por otra parte, porque el poder imaginativo del director le permite, apoyándose en su visión de la obra, imponer un contexto que sintoniza con la época actual hasta hacer desaparecer los vestigios de la obra original. Pero sobre todo porque en la construcción del espectáculo se cruzan lenguajes irreductibles (idiomáticos, simbólicos, culturales o físicos), que chocan, se influencian, se desconocen y, sin embargo, necesitan encontrar terrenos donde dialogar y trasladar fuerzas expresivas e interpretativas.

De esta forma, el acto de poner en escena se define como un acto permanente de traducción y de retraducción y se impone por encima de una necesidad de transferencia idiomática. Acto indispensable a la circulación continua de un lenguaje a otro y que se manifiesta también en la traducción constante que producen los actores para nutrir su creatividad escénica. Pero, como la propia traducción textual, parece una tarea imposible, sisifica, y a la vez indispensable, para que la obra original escrita llegue al espectador bajo una forma espectacular.

En una visión realmente moderna de la creación, esos principios implican incluir en ese ciclo de continua mutación el propio texto escénico para que ese componente esencial del espectáculo no quede ajeno a la dinámica viva y frágil del trabajo teatral, para que no se asiente en la estabilidad de la letra. Porque, aunque la creación contemporánea exija la profanación de los vestigios de la obra original, también las formas que produce tienden a cristalizarse y a morir por no reinventarse, y la exigencia mayor y vital de dicha creación es reconocer cuando se enfrenta a sus propios vestigios y lograr profanarlos, sin conocer a dónde lleva el paso siguiente. Es una tarea que se antoja imposible y arriesgada, pero vive del deseo eterno e infinito de traducir. 


\section{Bibliografía}

» Barrault, J-L. (1949). A propos de Shakespeare et du Théâtre. Paris: Éditions de La Parade.

" Bonnefoy, Y. (1982, marzo-abril). “Comment traduire Shakespeare”. Théâtrel Public (44), 50-55.

» Carrière, J-C. (1982, marzo-abril). “Naviguer au plus près”, entretien de Georges Banu. Théâtre/Public (44), 41-43.

"Pasqual, L. (1989). Programme de "Comme il vous plaira" de Shakespeare, mise en scène de Lluís Pasqual. Paris: Comédie Française.

»Malaplate, J. (1991). Introduction à Hamlet de William Shakespeare. Éd. Heurtematte, J. y Jones-Davies, M-T. Trad. Jean Malaplate. Paris: José Corti.

» Mesguich, D. (1977, 1er tr.). "Hamlet au Centre Dramatique National des Alpes”. Hamlet 1601-1977, Silex (3), 30-32.

» Meyers, B. (1982, marzo-abril). “Un accent très tonique”, entretien de Théâtre/ Public. Théâtre/Public (44), 72-73.

»Mnouchkine, A. (1982). "Le besoin d'une forme”, entretien de Jean-Michel Déprats. Théâtre/Public (46/47), 8-11.

»Seide, S. (1982, marzo-abril). “La traduction complétée par le jeu”, entretien de Georges Banu. Théâtre/Public (44), 6o-61.

»Vitez, A. (1978, enero). “Extraits de la conférence de presse d'Antoine Vitez - 12 Mai 1977 à lvry”, propos recueillis. Théâtre/Public (19), 17-22.

"Vitez, A. (1982, marzo-abril). “Le devoir de traduire”, entretien de Georges Banu. Théâtre/Public (44), p. 6-10. 